\title{
Paul's Ekklesia as a Civic Assembly
}

\author{
Understanding the People of God in their Politico-Social World
}

[Paulus' Ekklesia als Volksversammlung. Das Volk Gottes in seiner politisch-sozialen Welt.]

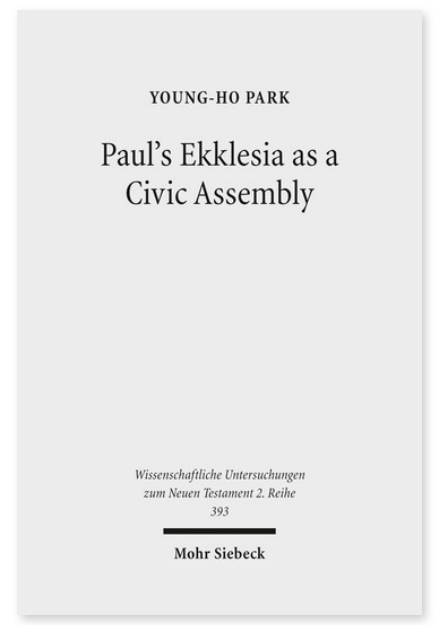

2015. X, 254 Seiten. WUNT II 393

ISBN 978-3-16-153256-6

DOI 10.1628/978-3-16-153256-6

eBook PDF $104,00 €$

ISBN 978-3-16-153060-9

fadengeheftete Broschur 104,00€
Veröffentlicht auf Englisch.

Das griechische Wort ekklesia bezeichnete ursprünglich die Bürgerversammlung aller Bewohner in der klassischen griechischen Demokratie. Young-Ho Park vertritt die Auffassung, dass die starke bürgerliche Konnotation dieses Begriffs in der politischen Kultur der hellenistischen und römischen Periode fortdauerte. Die Verwendung des Wortes ekklesia im Judentum zur Zeit des Zweiten Tempels muss also auch innerhalb dieser politischen Kultur verstanden werden, mit der die Juden wesentlich verbunden waren. Indem Paulus diesen bürgerlichen Begriff in seinen Briefen an die heidnischen Gemeinden übernahm, erschuf er ein symbolisches Universum, in dem die Christen sich selber als die ehrenwerten Bürger sahen, die die Stadt vor Gott repräsentierten. Dieser bürgerliche Charakter der Gemeinde wurde auch für Paulus' Lösung des KorintherProblems verwendet, wie man vor allem für das Abendmahl sehen kann, und versah die lokalen Gemeinden mit organisatorischen Richtlinien.

Young-Ho Park Born 1965; BA at Pusan National University; M. Div. and Th. M. at Presbyterian Theological Seminary, Seoul; STM at Yale Divinity School; 2012 PhD at University of Chicago; Professor of New Testament at Hanil University and Theological Seminary in Korea.
Jetzt bestellen:

https://mohrsiebeck.com/buch/pauls-ekklesia-as-a-civic-assembly-9783161532566?no_cache=1 order@mohrsiebeck.com

Telefon: +49 (0)7071-923-17

Telefax: $+49(0) 7071-51104$ 